14.01

Детектирование клеток, содержащих интернализованные

\title{
мультидоменные магнитные наночастицы оксида железа (II, III), методом магнитно-резонансной томографии
}

\author{
(C) Н.И. Енукашвили, ${ }^{1,2}$ И.Е. Коткас, ${ }^{2}$ Д.С. Боголюбов, ${ }^{1}$ А.В. Котова, ${ }^{1,2}$ И.О. Боголюбова, ${ }^{1}$ В.В. Багаева, ${ }^{2,3}$ \\ К.А. Левчук, ${ }^{2}$ И.И. Масленникова, ${ }^{2}$ Д.А. Иволгин, ${ }^{2,3}$ А.Ю. Артамонов, ${ }^{5}$ Н.В. Марченко, ${ }^{4}$ И.В. Миндукшев ${ }^{6}$ \\ ${ }^{1}$ Институт цитологии РАН, \\ 194064 Санкт-Петербург, Россия \\ ${ }^{2}$ Северо-Западный государственный медицинский университет им. И.И. Мечникова, \\ 195067 Санкт-Петербург, Россия \\ ${ }^{3}$ Покровский Банк стволовых клеток, \\ 199106 Санкт-Петербург, Россия \\ ${ }^{4}$ Научно-исследовательский институт детских инфекций, \\ 197022 Санкт-Петербург, Россия \\ ${ }^{5}$ Институт экспериментальной медицины, \\ 197376 Санкт-Петербург, Россия \\ ${ }^{6}$ Институт эволюционной физиологии и биохимии им. И.М. Сеченова \\ 194223 Санкт-Петербург, Россия \\ e-mail: n.enukashvily@incras.ru
}

Поступило в Редакцию15 декабря 2019 г.

В окончательной редакции 15 декабря 2019 г.

Принято к публикации 17 февраля 2020 г.

\begin{abstract}
Проведена оценка возможности применения непокрытых наночастиц оксида железа (II, III), полученных методом электрического взрыва в воздушной атмосфере, для получения меченых клеток с целью последующей их визуализации методом магнитно-резонансной томографии (МРТ) в тканях с помощью применяемых в клинике 1Т и 1.5T МРТ-сканеров. Показано, что клетки поглощали такие частицы при широком диапазоне их концентрации в среде без снижения пролиферативной активности, жизнеспособности и без изменений набора поверхностных маркеров, характерного для данного типа клеток. Наночастицы оксида железа, полученные методом электрического взрыва в атмосфере воздуха, обладали формой, близкой к сферической. Размер частиц по данным динамического бокового светорассеивания, лазерной дифракции и просвечивающей электронной микроскопии варьировал от 14 до $136 \mathrm{~nm}$. При этом частицы до $136 \mathrm{~nm}$ составляли $75 \%$, а частицы менее $36 \mathrm{~nm}-10 \%$. Широкий диапазон размеров частиц позволил подобрать параметры визуализации методом МРТ в тканях животных как при режиме Т2, так и при режиме Т1 релаксации.
\end{abstract}

Ключевые слова: наночастицы оксида железа $\mathrm{Fe}_{3} \mathrm{O}_{4}$, мезенхимные стромальные клетки, способы визуализации клеток in vivo, контрастирующие агенты для магнитно-резонансной томографии.

DOI: 10.21883/JTF.2020.09.49671.402-19

\section{Введение}

Мезенхимные стволовые клетки (МСК) дают начало различным клеточным популяциям, составляющим стромальную основу всех органов и тканей организма человека. МСК рассматривают как основной источник материала для клеточных технологий в регенеративной медицине.

Один из ключевых вопросов - кинетика распределения клеток, вводимых в организм. Без подтверждения факта присутствия клеток в месте инъекции или в очаге заболевания наличие терапевтического эффекта клеточных препаратов не может считаться доказанным, поскольку их действие основано на паракринных механизмах. Необходима разработка метода прижизненного мечения клеток для изучения кинетики биомедицинских клеточных продуктов (БМКП) в организме крупных животных и человека. Перспективным считается использование метода магнитно-резонансной томографии (МРТ) для визуализации трансплантата. Использование МРТ требует разработки метода прижизненного мечения клеток контрастирующими агентами [1].

Наночастицы оксида железа $\mathrm{Fe}_{3} \mathrm{O}_{4}$ (магнетит) рассматриваются в качестве материала, предположительно отвечающего этим требованиям [2]. Магнетит содержит двух- и трехвалентные ионы железа. Номенклатурное название по IUPAC-оксид железа (II,III), химическая формула $\mathrm{Fe}_{3} \mathrm{O}_{4}$ или $\mathrm{FeO} \cdot \mathrm{Fe}_{2} \mathrm{O}_{3}$. Структурная формула $\left[\mathrm{Fe}^{3+}\right]_{\mathrm{Td}}\left[\mathrm{Fe}^{3+}, \mathrm{Fe}^{2+}\right]_{\mathrm{Oh}} \mathrm{O}_{4}^{2-}$, что означает наличие тетраэдрической подрешетки, содержащей ионы $\mathrm{Fe}^{3+}$, и октаэдрической подрешетки, содержащей ионы $\mathrm{Fe}^{3+}$ и $\mathrm{Fe}^{2+}$. Тетраэдрические и октаэдрические ионы $\mathrm{Fe}^{3+}$ 
составляют подрешетки $A$ и $B$. Восемь расположенных октаэдрических ионов $\mathrm{Fe}^{2+}$ составляют подрешетку $C$. Между ионами подрешеток и существует антиферромагнитное обменное взаимодействие, приводящее к взаимной компенсации их суммарных спиновых магнитных моментов, а между ионами подрешеток и существует обменное взаимодействие, приводящее к параллельной ориентации их суммарных спиновых магнитных моментов. В результате магнитный момент наночастицы равен суммарному спиновому магнитному моменту электронов ионов $\mathrm{Fe}^{2+}$, находящихся в подрешетке $[3,4]$.

В зависимости от ориентации диполей в магнитном поле и остаточной магнетизации различают диамагнетики, парамагнетики, ферромагнетики, ферримагнетики и антиферромагнетики. В случае наночастиц в некоторых случаях мы имеем дело с еще одной формой магнетизма - суперпарамагнетиками. Для них вследствие малого размера характерен переход в однодоменное состояние, когда частица равномерно намагничена по всему объему. Магнетизация наночастицы равна нулю в отсутствие магнитного поля [5]. Такие частицы давно используют в качестве контрастирующего агента в МРТ [6]. Благодаря незначительной способности к агломерации наночастицы не блокируют кровеносные сосуды и не служат причиной тромбозов [7]. Однако эти частицы получают различными способами, чаще всего в ходе химических реакций, что приводит к загрязнению продукта цитотоксичными материалами. Для улучшения их свойств требуются органические покрытия [8,9], но показано, что покрытие может повреждаться до интернализации частицы клеткой или уже в самой клетке [10]. Наночастицы оксида железа (IONP, iron oxide nanoparticles) диаметром более 20-40 nm (в зависимости от степени окисления железа), но менее $100 \mathrm{~nm}$, не обладают свойством суперпарамагнитности, тем не менее они могут использоваться для контрастирования при МРТ [5,11]. Возможно их получение методом электрического взрыва в воздушной атмосфере $[12,13]$, что позволяет снизить количество цитотоксичных примесей. При этом для введения их в клетки необходима разработка соответствующих методов и оценка влияния частиц на свойства МСК: после мечения они должны сохранять свой терапевтический потенциал.

Цель проекта: Разработка протокола мечения клеток IONP, полученными методом электрического взрыва в воздушной атмосфере, для последующей визуализации их в тканях с помощью применяемых в клинике 1Т и 1.5T МРТ-сканеров.

\section{1. Материалы и методы исследования}

\subsection{IONP}

Исследования проводили на МСК пупочного канатика (ПК) и жировой ткани. В качестве контрастирующего агента использовали непокрытые IONP, соответствующие ТУ 1791-003-36280340-2008 („Передовые порошковые технологии“, Россия). Согласно описаниям производителя, нанопорошок оксида железа (II, III), магнетит; химическая формула вещества: $\mathrm{Fe}_{3} \mathrm{O}_{4}$. Нанопорошок получен методом электрического взрыва проводника в атмосфере воздуха и содержит $\mathrm{Fe}_{3} \mathrm{O}_{4}$ не менее 99 mass.\%. Согласно спецификации производителя, среднеарифметический размер частиц 80-110 nm. Перед использованием готовили в стерильных условиях навески IONP по $100 \mathrm{mg}$ и стерилизовали автоклавированием и/или обработкой ультрафиолетовым излучением. Далее в стерильных условиях частицы смешивали с культуральной средой (см. раздел „Клеточные культуры“), так, чтобы получить стоковый раствор $10 \mathrm{mg} / \mathrm{ml}$. После этого проводили обработку суспензий ультразвуком в течение 10 min при частоте $35 \mathrm{kHz}$ („Сапфир“, Россия) и сразу же после обработки использовали для приготовления суспензий IONP в культуральной среде с концентрацией частиц $3,30,100,300,600 \mu \mathrm{g} / \mathrm{ml}$.

\section{2. Измерение размеров и скорости агрегации IONP}

Оценку размера частиц проводили методом динамического светорассеяния (Dinamic light scattering, DLS) на приборе DelsaMaxPro (Beckman-Coulter, CША), а также методом лазерной дифракции, используя лазерный дифракционный анализатор размера частиц „Ласка-ТД“ (БиоМедСистем, Россия; Госреестр СИ РФ № $72792-$ 18). Лазерный дифракционный анализатор также использовали для изучения скорости агрегации частиц.

Метод DLS позволяет измерить поступательную диффузию молекул в растворах, возникающую вследствие броуновского движения [14]. Диффузия молекул приводит к изменению их относительного положения, что, в свою очередь, вызывает флуктуацию интенсивности рассеянного света вследствие интерференции. Малые молекулы диффундируют быстро и соответственно генерируют быстро флуктуирующие сигналы. Большие молекулы генерируют медленно флуктуирующие сигналы. Коэффициент диффузии флуктуации определяется с помощью автокорреляционного анализа. При допущении, что молекула представляет собой сферу, для расчета ее гидродинамического радиуса используется уравнение Стокса-Эйнштейна: $D=\frac{R T}{N} \frac{1}{6 \pi k r}$, где $D-$ коэффициент диффузии, $r$ - радиус.

Определение гидродинамического радиуса методом DLS проводили, используя суспензию IONP $(300 \mu \mathrm{g} / \mathrm{ml})$, в дистиллированной воде. Анализируемый образец оксида железа непосредственно перед измерением был обработан ультразвуком в течение $15 \mathrm{~min}$. Считывание данных проводили сразу после обработки ультразвуком, через 10 и $15 \mathrm{~min}$. Образец находился в полистирольной кювете, длина волны измерения $532 \mathrm{~nm}$, длительность измерения составляла $5 \mathrm{~s}$, количество измерений -3 . 
Для более детальной оценки размеров частиц и скорости агрегации IONP $(300 \mu \mathrm{g} / \mathrm{ml})$ в физиологическом растворе проводили определение гранулометрического (фракционного) состава суспензии методом лазерной дифракции. В общем виде метод лазерной дифракции реализуется по следующей схеме: через кювету с суспензией частиц пропускается световой пучок от когерентного излучателя (лазера); рассеянное излучение под разными углами регистрируется с помощью многоэлементного детектора; по полученной зависимости интенсивности рассеянного излучения от угла рассеяния осуществляется расчет размеров частиц и распределения частиц по размерам. Для оценки функции распределения частиц по размерам использовали алгоритм программы LaSca_32. В качестве стандартов использовались: SRM659 и SRM1003c (NIST), CML latex $6 \mu \mathrm{m}, 10 \mu \mathrm{m}, 16 \mu \mathrm{m}$ (Thermofisher Invitrogen, CША). Скорость агрегации частиц характеризовали по данным кинетики прямого светорассеяния под углом $1^{\circ}[15]$. В каждом измерении определяли распределение частиц по размерам, представленное интегральной и дифференциальной функцией. Количественно гранулометрический состав характеризовали квантилями распределения $(D 10, D 25, D 50, D 75, D 99)$, представляющими долю частиц с размерами, меньшими данного размера. Например, $D 50=0.25 \mu$ m означает, что $50 \%$ частиц имеют диаметр не больше $0.25 \mu \mathrm{m}$.

\section{3. Просвечивающая электронная микроскопия}

Размер, форму частиц и внешний вид агрегатов, поглощенных клетками, оценивали с помощью электронной микроскопии.

Клетки после инкубации со IONP в различных концентрациях снимали с подложки обработкой трипсинверсеном, отмывали фосфатно-солевым буфером, помещали суспензию в культуральную среду в пробирку $2 \mathrm{ml}$. Далее клетки осаждали, фиксировали 2.5\%-ным глутаральдегидом на $0.05 \mathrm{M}$ какодилатном буфере с добавлением 8.5\% сахарозы ( $\mathrm{pH} 7.3)$ с последующей фиксацией в 2\%-ном $\mathrm{OsO}_{4}$ на том же буфере, после чего обезвоживали в серии спиртов восходящей концентрации и заключали в смолу Spurr (Electron Microscopy Sciences, США). Ультратонкие срезы контрастировали уранилацетатом и цитратом свинца и просматривали с помощью просвечивающего электронного микроскопа Libra-120 (Carl Zeiss) при ускоряющем напряжении $80 \mathrm{kV}$.

\section{4. Клеточные культуры}

\subsection{1. Соблюдение этических стандартов}

Все процедуры, выполненные в исследовании с участием людей, соответствуют этическим стандартам локального и/или национального комитета по исследовательской этике и Хельсинкской декларации 1964г. и ее последующим изменениям или сопоставимым нормам этики. Для получения культур МСК в качестве основного материала для исследования использованы ткани пупочного канатика и жировой ткани доноров без системных заболеваний при наличии информированного согласия.

\subsection{2. Получение первичных культур МСК жировой ткани}

МСК жировой ткани получали методом ферментации фрагмента жировой ткани, удаленного хирургическим способом. Образцы пупочных канатиков были получены при неосложненных родах. МСК выделяли по собственной методике [16,17]: пупочную вену канатика промывали раствором Версена, заполняли $0.1 \%$ раствором коллагеназы I и IV типа и инкубировали в течение $30 \mathrm{~min}$ при $37^{\circ} \mathrm{C}$. Затем вену промывали фосфатно-солевым буфером, повторно заполняли раствором коллагеназ и инкубировали в течение $30 \mathrm{~min}$ при $37^{\circ} \mathrm{C}$. Полученную взвесь клеток отмывали от фермента центрифугированием $(400 \mathrm{~g}, 10 \mathrm{~min})$ и высевали во флаконы при плотности $100-400$ тыс.cells $/ \mathrm{cm}^{2}$. Смену среды проводили через 3 суток.

\section{5. Криоконсервация}

Криоконсервацию проводили по стандартному протоколу $\left(1^{\circ} \mathrm{C} / \mathrm{min}\right)$ с использованием программируемого замораживателя. Для оценки изменения параметров клеток их размораживали через 31 день после заморозки.

\section{6. Мечение клеток. Магнитная сепарация. Измерение скорости пролиферации и иммунофенотипа}

Частицы (предварительно обработанные ультразвуком) вносили в культуральную среду в различных концентрациях в $3,30,100,300,400,600 \mu \mathrm{g} / \mathrm{ml}$ и инкубировали в течение $8 \mathrm{~h}$. Затем среду удаляли и далее клетки снимали с подложки, меченые клетки отделяли методом магнитной сепарации с помощью магнитного мини-штатива (Силекс, Россия) и вносили в лунки 6-луночных планшетов в количестве 10 тыс. на лунку. Построение кривой роста проводили стандартным методом - подсчитывая в камере Горяева число клеток в лунках через 2, 4, 6 и 8 дней после посева.

Иммунофенотипирование клеток проводили с использованием проточного цитометра Navios (Beckman Coulter, США) с использованием полупроводниковых диодных лазеров с длиной волны излучения 488 и $638 \mathrm{~nm}$ и стандартным набором светофильтров от производителя (синий лазер: 525/40, 575/30, 614/20, 695/30, 755LP; красный лазер: 660/20, 725/20, 755 LP). Использовали следующие панели моноклональных антител (Beckman 


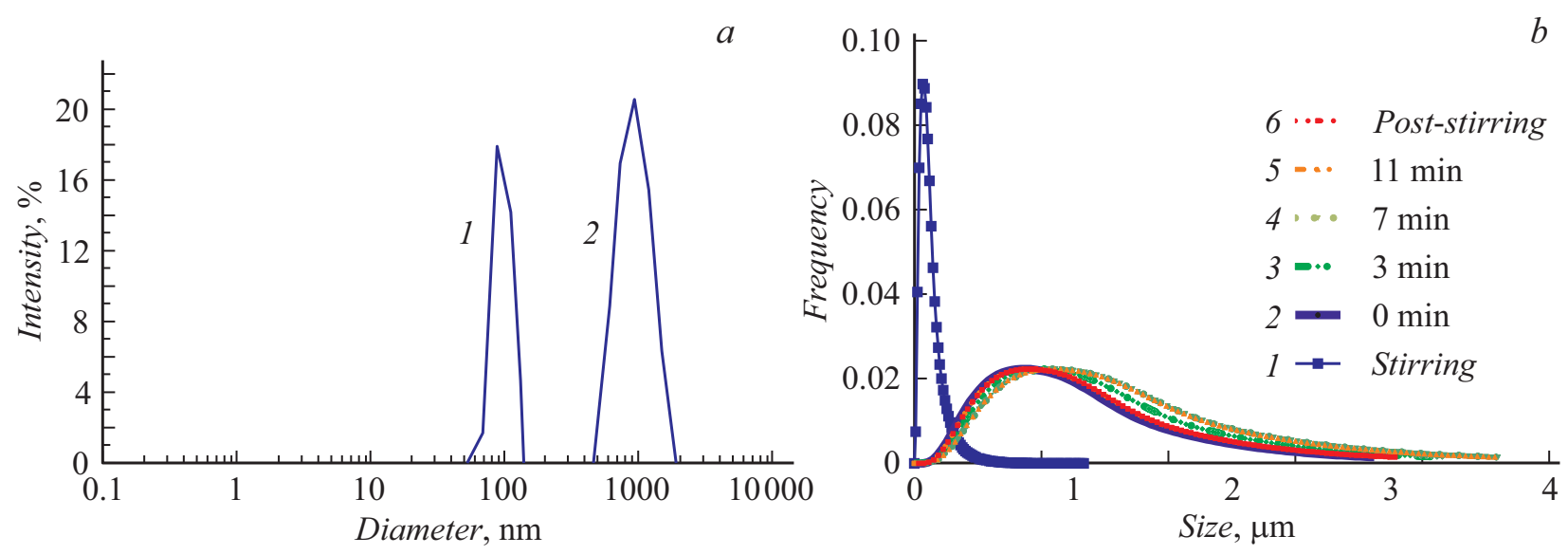

Рис. 1. Анализ размеров IONP в суспензии и скорости их агрегации методом DLS $(a)$ и лазерной дифракции $(b)$. $a-$ пик $1-$ референсные латексные частицы диаметром $100 \mathrm{~nm}$, пик 2 - образец, $b-1$ - образец $(300 \mu \mathrm{g} / \mathrm{ml})$ после ультразвуковой обработки при постоянном перемешивании, 2-5 - через 0, 3, 7, 11 min после выключения мешалки, 6 - при повторном включении мешалки через $180 \mathrm{~min}$. По оси $X-$ диаметр частиц в $\mu \mathrm{m}$, по оси $Y-$ вероятностная частота.

Таблица 1. Интегральный гранулометрический состав в $\mu \mathrm{m}$ суспензии IONP -- долевое распределение частиц по квантилям*

\begin{tabular}{c|c|l|l|l|l|l|c}
\hline Квантиль & Перемешивание & \multicolumn{1}{|c|}{$0 \mathrm{~min}$} & $3 \mathrm{~min}$ & $7 \mathrm{~min}$ & $11 \mathrm{~min}$ & $180 \mathrm{~min}$ & Постперемешивание \\
\hline$D 10=$ & 0.0367 & 0.4271 & 0.4905 & 0.5421 & 0.5392 & 0.562 & 0.4466 \\
$D 25=$ & 0.0551 & 0.6436 & 0.739 & 0.8168 & 0.8125 & 0.914 & 0.6729 \\
$D 50=$ & 0.0864 & 0.9771 & 1.122 & 1.24 & 1.233 & 1.34 & 1.022 \\
$D 75=$ & 0.136 & 1.48 & 1.7 & 1.879 & 1.869 & 2.01 & 1.548 \\
$D 90=$ & 0.2116 & 2.218 & 2.546 & 2.814 & 2.799 & 2.81 & 2.318 \\
$D 99=$ & 0.5343 & 4.183 & 4.804 & 5.309 & 5.281 & 5.18 & 4.374 \\
AVG & 0.1074 & 1.182 & 1.357 & 1.5 & 1.491 & 1.564 & 1.231
\end{tabular}

Примечание. * - например, значение квантиля $D 50=0.0864$ означает, что в данной суспензии $50 \%$ частиц обладали диаметром $0.0864 \mu$ m и менее. Каждый последующий класс крупности включает в себя предыдущий. AVG - среднее арифметическое в каждой точке измерения.

Coulter) для определения положительных и отрицательных маркеров иммунофенотипа мезенхимных стромальных клеток: CD44-FITC/CD73-PE/CD9-PC5/CD105-PC7 и CD34-FITC/CD117-PE/CD14-PC5/CD45-PC7. Гейтирование графиков флуоресценции клеточных маркеров проводили по „живым“ клеткам (выделены по параметрам прямого и бокового светорассеяния и окрашиванию 7-аминоактиномицином - 7-AAD). Границы аутофлуоресценции определяли по неокрашенному контрольному образцу. Границы неспецифического связывания антител определяли с помощью изотипических контролей (иммуноглобулины мыши, конъюгированные с FITC, PE, PC5, РС7). В каждой пробе анализировали не менее 20000 „целевых событий“ (событий определенных как жизнеспособные клетки на основании значений прямого и бокового светорассеяния и отсутствия окрашивания 7-AAD жизнеспособных клеток)

\subsection{MPT}

Клетки метили, как описано выше при концентрации частиц 100, 200 и $300 \mu \mathrm{g} / \mathrm{ml}$. Для первичной оценки $5 \cdot 10^{6}$ клеток ресуспендировали в $5 \mathrm{ml}$ физиологиче- ского раствора и помещали в шприцы $5 \mathrm{ml}$. Непосредственно перед сканированием шприцы с клетками сильно встряхивали и удаляли инъекционную иглу. Шприцы укладывали на поверхность фантома (муляжа) подходящего размера. После подбора условий и оценки оптимальной концентрации частиц при мечении на следующем этапе меченые клетки инъецировали во фрагмент $(25 \times 15 \times 5 \mathrm{~cm})$ печени крупного рогатого скота. Сканирование проводили на магнитно-резонансном томографе Siemens Espree, а также на PHILIPS Ingenia c напряженностью магнитного поля $1.5 \mathrm{~T}$.

\section{8. Статистическая обработка данных}

Для каждого образца эксперимент повторяли не менее трех раз. Для оценки значимости различий $(p<0.05)$ при анализе пролиферативной активности использовали множественный t-test. Анализ полученных данных и построение графиков проводили в программе GraphPad Prism 7. Данные представлены в виде среднего \pm стандартное отклонение. 


\section{2. Результаты}

\section{1. Оценка размеров и скорости агрегации частиц}

В отсутствие обработки ультразвуком частицы образуют агрегаты размером $1-3 \mu \mathrm{m}$. Обработка ультразвуком приводила к диссоциации агрегатов (табл. 1, рис. 1). Установлено методом DLS, что гидродинамический радиус изучаемых агрегатов частиц оксида железа составляет $473 \mathrm{~nm}$, расчетный диаметр - $946 \mathrm{~nm}$ (рис. 1,a). Так же показано, что результат измерения не зависит от того, проводилось ли измерение непосредственно после обработки ультразвуком, через $10 \mathrm{~min}$ или через $15 \mathrm{~min}$. При оценке методом лазерной дифракции установлено, что после обработки ультразвуком при постоянном интенсивном перемешивании IONP, взвешенных в физиологическом растворе, агрегаты не образовывались, детектировались мелкие частицы до $136 \mathrm{~nm}$ (рис. 1,b). Частицы $\leq 136 \mathrm{~nm}$ составляли 75\% IONP в анализируемой суспензии (табл. 1). Несмотря на заявленные производителем спецификации $(80-100 \mathrm{~nm})$, методом лазерной дифракции показано, что $10 \%$ частиц суспензии обладали размером $\leq 36 \mathrm{~nm}$ (табл. 1), т. е. приближались по своим параметрам к суперпарамагнитным наночастицам оксида железа. Однако при остановке перемешивания агрегаты IONP образовывались в первые секунды, и далее суспензия оставалась стабильной в течение длительного времени. Размер агрегатов практически не менялся в течение всего времени измерения. Повторное включение мешалки через $3 \mathrm{~h}$ не приводило к значимому изменению размера агрегатов (табл. 1, рис. $1, b)$.

\section{2. Исследование формы и диаметра IONP методом просвечивающей электронной микроскопии}

Методом лазерной дифракции установлено, что небольшой процент IONP обладает диаметром менее $36 \mathrm{~nm}$. Оценить размер частиц более точно не позволяла разрешающая способность метода. Однако для использования исследуемых IONP в качестве контрастирующего вещества для МРТ очень важно проверить присутствие в препарате частиц диаметром $\leq 30 \mathrm{~nm}$ (по некоторым оценкам - $20 \mathrm{~nm}$ ), поскольку от этого зависит выбор параметров МРТ - использование режимов Т1- или Т2-взвешенности. Кроме этого, ни метод лазерной дифракции, ни метод DLS не дают возможность определить форму частиц. Поэтому размер и форму частиц оценивали дополнительно методом просвечивающей электронной микроскопии (рис. 2). Обнаружено, что большинство частиц, используемых IONP, обладали правильной сферической или гексагональной формой. Размер более 70\% частиц находился в диапазоне 40-130 nm, что согласуется с данными, описанными выше. Однако в суспензии клеток присутствовали

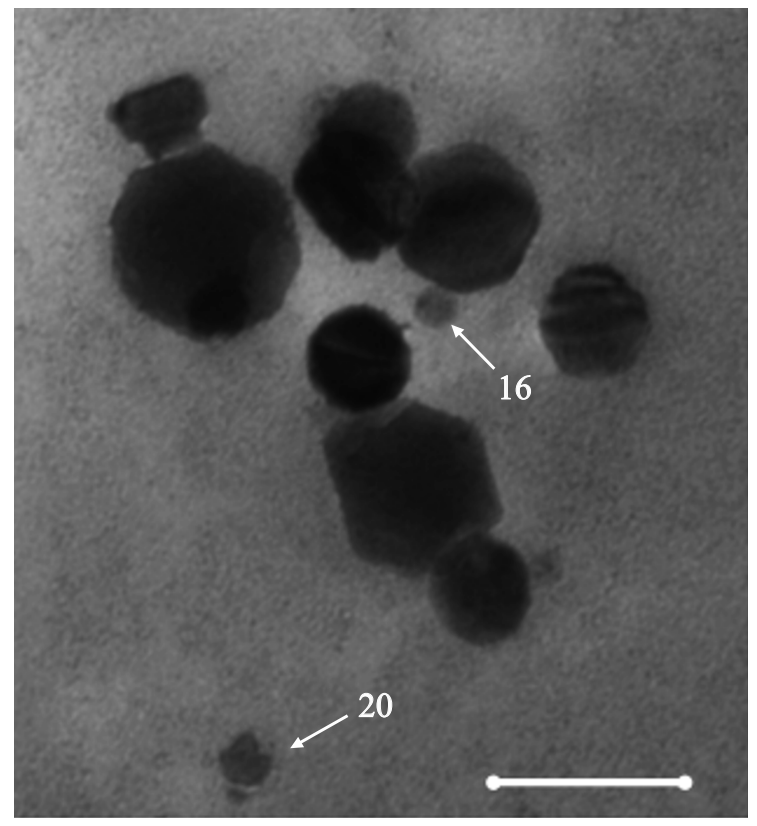

Рис. 2. Просвечивающая электронная микроскопия IONP. Масштабная линейка $-100 \mathrm{~nm}$. Стрелками отмечены IONP диаметром $\leq 20 \mathrm{~nm}$. Цифры рядом со стрелками - размер в нанометрах.

также частицы $\leq 20 \mathrm{~nm}$ (рис. 2). Доля таких частиц не превышала $10 \%$.

\section{3. Морфология, жизнеспособность и иммунофенотип MCK, содержащих IONP}

Включение наночастиц относительно крупного диаметра, обладающих способностью образовывать агрегаты, может влиять на такие базовые характеристики клеток, как жизнеспособность, способность к пролиферации и иммунофенотип (набор поверхностных маркеров, характерных для данного типа клеток). Поэтому была проведена оценка этих параметров для клеток, содержащих IONP.

Первоначально использовали для мечения IONP в концентрации $100-600 \mu \mathrm{g} / \mathrm{ml}$, не обрабатывая частицы ультразвуком, однако это приводило к включению в клетки частиц слишком большого диаметра и гибели клеток. Обработка ультразвуком позволила добиться включения в клетки частиц меньшего диаметра при концентрации частиц 3-300 $\mu \mathrm{g} / \mathrm{ml}$ (рис. 3). Однако при концентрациях 400 и $600 \mu \mathrm{g} / \mathrm{ml}$ отмечена значительная агрегация IONP во время инкубации с клетками за счет высокой концентрации частиц.

При визуальной оценке клеток для концентраций IONP $3-300 \mu \mathrm{g} / \mathrm{ml}$ изменений морфологии, различимых на световом уровне при общем увеличении до $\times 400$, обнаружено не было. Различимость IONP в клетках при данном увеличении $(400-$ объектив $\times 40$, окуляр $\times 10)$ 

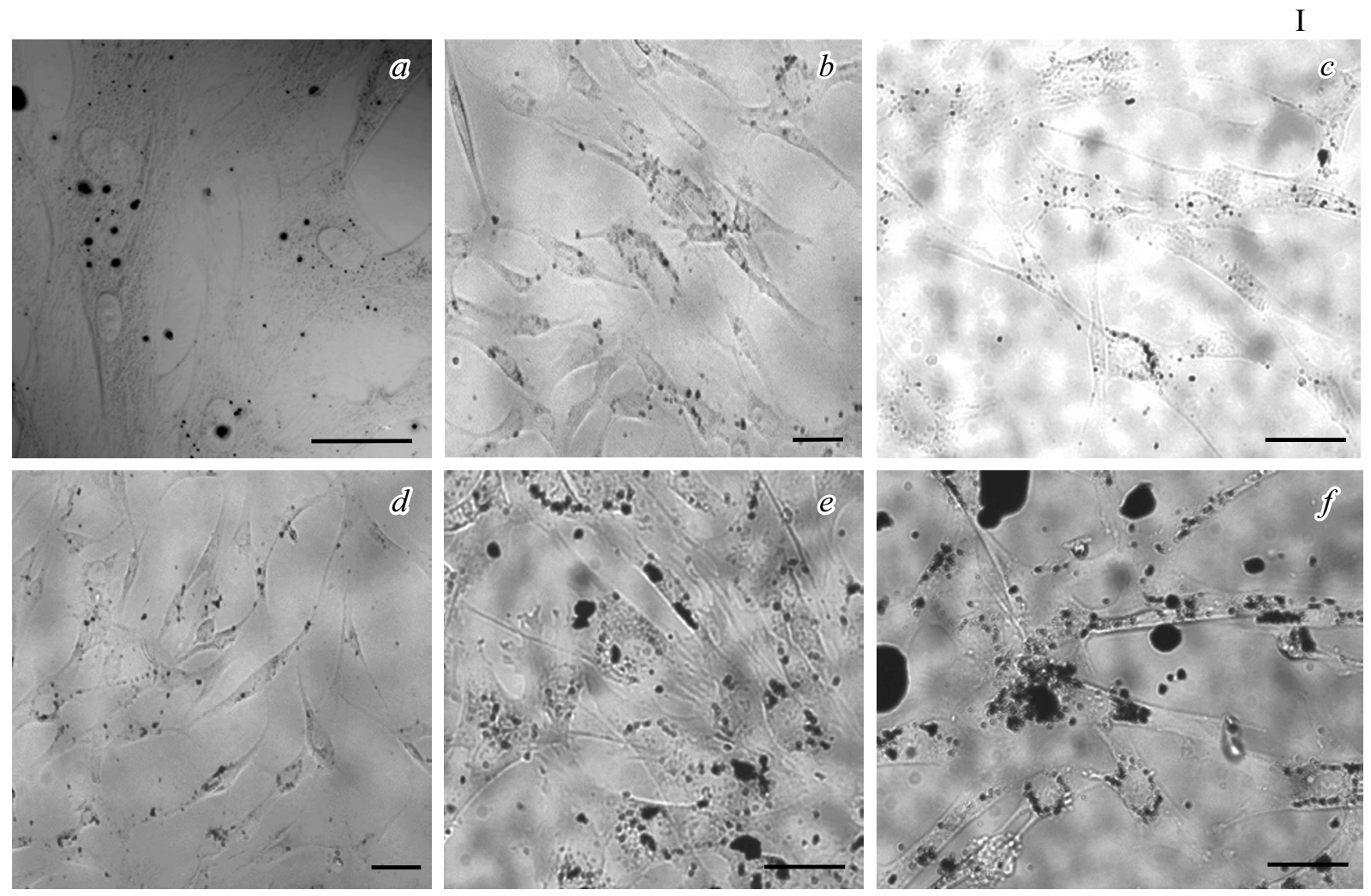

II
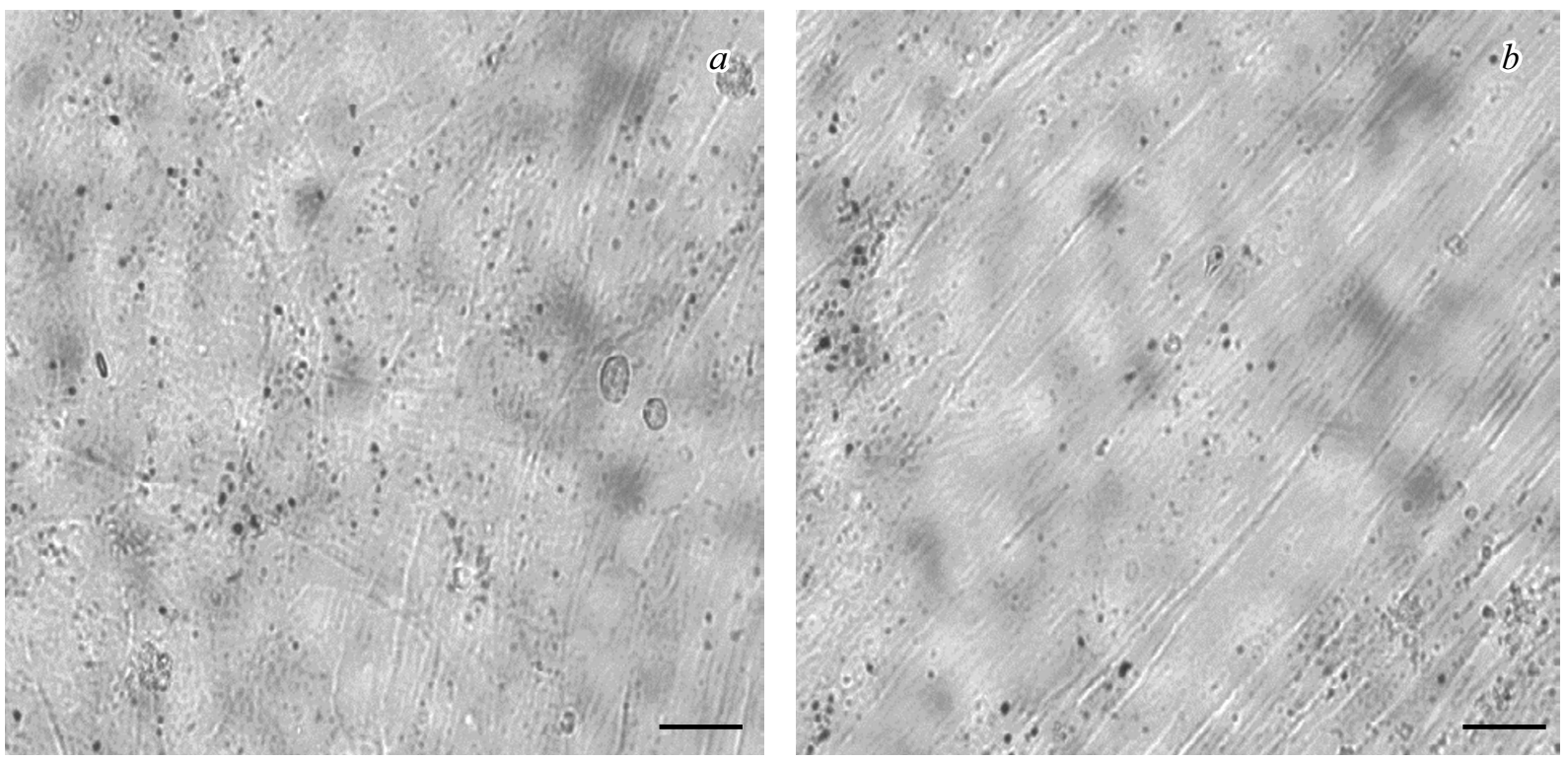

Рис. 3. Морфология клеток после инкубации с IONP. $a-f$ - сразу же после инкубации с IONP в концентрациях $3,30,100,300$, $400,600 \mu \mathrm{g} / \mathrm{ml}$ соответственно. $g-h$ - культура, обработанная IONP, $300 \mu \mathrm{g} / \mathrm{ml}$ после 2-го $(a)$ и 4-го $(b)$ пассирования в условиях стандартного культивирования. Масштабный отрезок $-20 \mu \mathrm{m}$. Изображение $a$ получено с использованием модуля получения изображения в проходящем свете во время лазерного сканирования микроскопа Olympus FV3000 (Nikon, Japan), остальные с использованием инвертированного светового микроскопа Axio Vert.A1 (Carl Zeiss, Germany).

говорит о том, что клетки поглощают не только одиночные частицы, но и их агрегаты.

При использовании IONP в концентрациях $3-300 \mu \mathrm{g} / \mathrm{ml}$ не наблюдали снижения пролиферативной активности клеток, а также изменения иммунофенотипа и жизнеспособности клеток по сравнению с контрольными клетками той же культуры, не обработанной IONP. Однако при использовании IONP в концентрации $600 \mu \mathrm{g} / \mathrm{ml}$ скорость пролиферации клеток снижалась (рис. 4). 
Таблица 2. Иммунофенотип и жизнеспособность клеток после обработки IONP по данным проточной цитометрии

\begin{tabular}{|c|c|c|c|}
\hline \multirow{3}{*}{ Маркеры } & \multicolumn{3}{|c|}{ Иммунофенотип, \% } \\
\hline & \multicolumn{2}{|c|}{ После обработки IONP } & \multirow{2}{*}{$\begin{array}{l}\text { Референсные значения } \\
\text { (без обработки IONP) }\end{array}$} \\
\hline & $3 \mu \mathrm{g} / \mathrm{ml}$ & $300 \mu \mathrm{g} / \mathrm{ml}$ & \\
\hline CD90 & $99.8 \pm 0.99$ & $98.2 \pm 0.85$ & $95-100$ \\
\hline CD105 & $98.0 \pm 0.65$ & $99.1 \pm 0.65$ & $95-100$ \\
\hline CD73 & $99.2 \pm 0.75$ & $98.0 \pm 0.95$ & $95-100$ \\
\hline CD44 & $98.8 \pm 1.75$ & $98.4 \pm 0.75$ & $95-100$ \\
\hline CD45 & $0.8 \pm 0.45$ & $1.4 \pm 0.55$ & $0-5$ \\
\hline CD14 & $0.5 \pm 0.25$ & $0.5 \pm 0.25$ & $0-5$ \\
\hline CD34 & $0.2 \pm 0.1$ & $0.5 \pm 0.1$ & $0-5$ \\
\hline CD117 & $0.05 \pm 0.01$ & $0.03 \pm 0.01$ & $0-5$ \\
\hline \multicolumn{4}{|c|}{ Жизнеспособность, \% } \\
\hline (7-AAD) & $92.1 \pm 2.4$ & $90.2 \pm 3.5$ & $>90$ \\
\hline
\end{tabular}

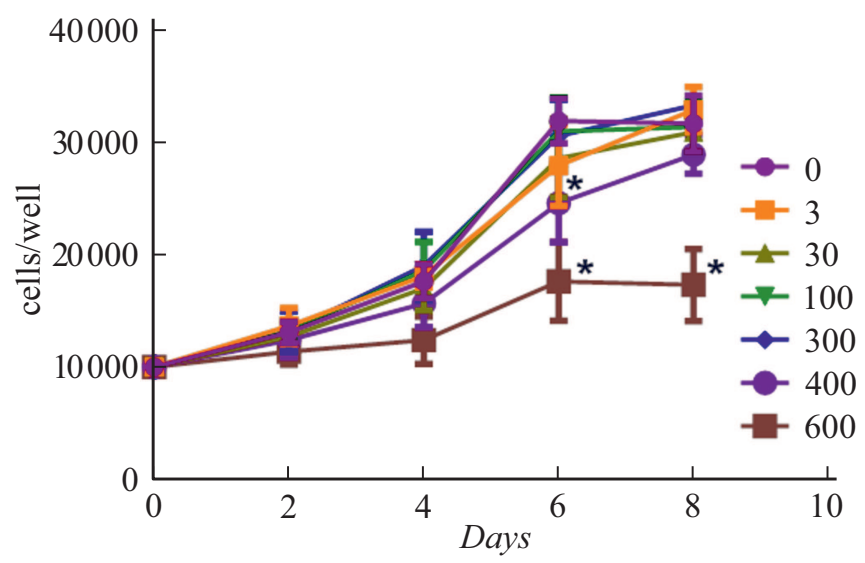

Рис. 4. Пролиферативная активность клеток, обработанных различными концентрациями IONP. По оси абсцисс - дни после пересева, по оси ординат - количество клеток в лунке планшета. Концентрация IONP $(\mu \mathrm{g} / \mathrm{ml})$ указана в легенде графика. Смена среды производилась каждые 3 days. ${ }^{*}-$ $p<0.05$ по сравнению с контрольной культурой в тот же день культивирования.

Согласно определению МСК, данному Международным обществом клеточной терапии, и которое является сегодня наиболее общепринятым, существует определенный набор поверхностных лигандов на мембране этих клеток [18]. Эти лиганды могут быть детектированы методом проточной цитометрии клеток, обработанных антителами к данным поверхностным маркерам. Поэтому мы проанализировали набор специфических маркеров с помощью панелей антител, описанных в разд. 1 (табл. 2). Исследовали иммунофенотип клеток, обработанных минимальной и максимальной концентрациями IONP, из диапазона, не оказывающего влияния на пролиферативную активность и морфологию клеток (3 и $300 \mu \mathrm{g} / \mathrm{ml}$, рис. 3,4$)$. В обоих случаях достоверных отличий от референсных значений лаборатории выявлено не было.

\section{4. Криоконсервация клеток, содержащих IONP}

Для облегчения работы с клетками, меченными IONP, удобным решением является заготовка нескольких аликвот таких клеток с их последующей криоконсервацией. Такой подход дает возможность работать с клетками, меченными в одинаковых условиях и тем самым стандартизовать проводимые эксперименты. Поэтому была исследована возможность криоконсервации клеток после введения в них IONP (рис. 5).

После размораживания и удаления криопротектора в клетках хорошо были различимы наночастицы. Культура клеток состояла из округлых как меченых, так и немеченых клеток. Частицы IONP присутствовали внутри клеток. Клетки не утрачивали способности прикрепляться к субстрату и в течение 5 days образовывали монослой, скорость их пролиферации не отличалась от пролиферации немеченых клеток того же донора, выведенных из криоконсервации в тот же день, в тех же условиях (рис. 5,f). На протяжении всех 6 days культивирования в клетках обнаруживались IONP, хотя количество в клетках снижалось (рис. 5, $a-e$ ), вероятнее всего за счет распределения между дочерними клетками, так как свободных IONP в культуральной среде не обнаруживали.

\section{5. Визуализация клеток методом МРТ}

После подбора параметров сканирования удалось визуализировать клетки с IONP в шприцах и сравнить сигнал с сигналом от IONP без клеток (рис. 6,a). Первым образцом слева располагался шприц без непокрытых наночастиц оксида железа, далее 3 шприца последовательно с различной концентрацией IONP. Справа шприц содержащий суспензию IONP. На изображении на рис. 6, a IONP в суспензии выявляли в T2-TSEрежиме в виде участков пониженного МР-сигнала различной интенсивности, что связано с тем, что в образцах присутствуют частицы разного размера (рис. 1,2).

Сбор данных и в образцах, и в тканях печени осуществляли всеми типами взвешенности (Т1 и Т2). Наиболее предпочтительной в данном виде исследования оказалась последовательность $\mathrm{T}^{*}$ gre.

На Т1 взвешенных изображениях (рис. $6, b$ ) отчетливо видны места инъекций препарата в ткань печени в виде понижения МР-сигнала на фоне неизмененной ткани за счет того, что основную часть IONP составляют мультидоменные частицы.

На T2 WI с подавлением сигнала от жировой ткани отчетливо видна жидкость под капсулой в месте инъекции с повышением интенсивности МР-сигнала, а зона скопления клеток, меченных оксидом железа, - 

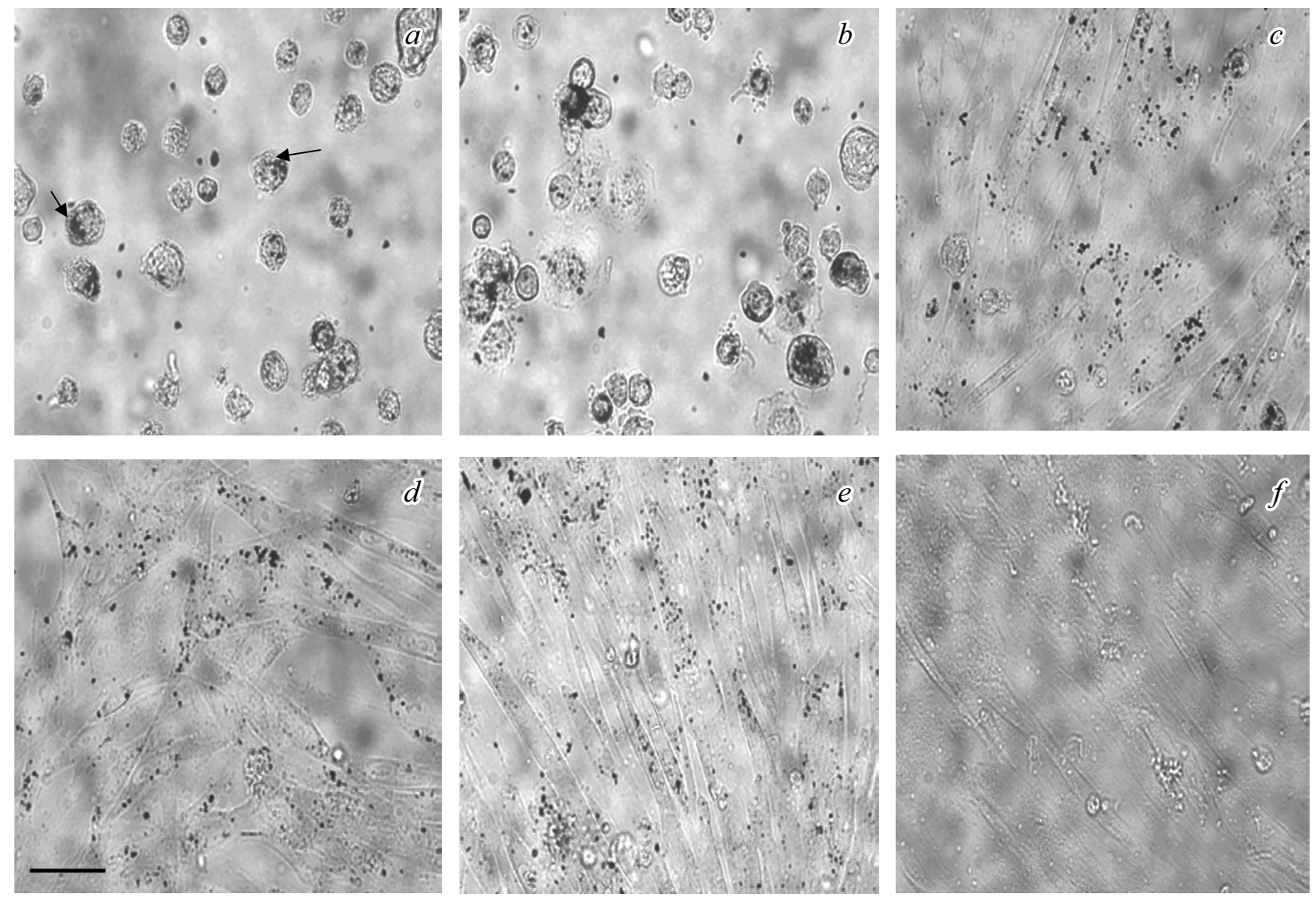

Рис. 5. Сохранность IONP в клетках после криоконсервации. Меченые клетки были заморожены и хранились 31 days в жидком азоте. Далее клетки были разморожены и прокультивированы 5 days. Представлены изображения клеток $(a)$ сразу после разморозки, IONP (отмечены стрелками) хорошо различимы при микроскопии в проходящем свете, $b-e-$ через $2,24,48$, $120 \mathrm{~h}$ после вывода из криоконсервации, $f$ - контрольные клетки, не содержащие наночастиц на пятые сутки после вывода из криоконсервации. Масштабный отрезок $-20 \mu \mathrm{m}$.

пониженным, так как суперпарамагнитные IONP используются как Т2-релаксанты (рис. 6,c).

Т2* gre - взвешенные последовательности, используемые для обнаружения дезоксигенированного гемоглобина, метгемоглобина или гемосидерина в повреждениях и тканях, а также в качестве регистрирующей последовательности для контрастного препарата с оксидами железа при поражениях печени. В данном случае были зафиксированы клетки с оксидом железа - IONP, инъецированные во фрагмент ткани печени крупного рогатого скота, характеризовались зонами отчетливого выпадения МР-сигнала (рис. 6, $d$ ).

\section{3. Обсуждение полученных результатов}

В проведенных нами исследованиях показано, что клетки, по крайней мере МСК, способны поглощать непокрытые IONP сравнительно крупного диаметра (рис. 2), не утрачивая жизнеспособности и основных характеристик - иммунофенотипа и скорости пролиферации. Для мечения можно использовать широкий диапазон концентраций IONP от 3 до $300 \mu \mathrm{g} / \mathrm{ml}$. Однако для детекции на клинических МРТ сканерах оптимальной является концентрация 100-300 $\mu \mathrm{g} / \mathrm{ml}$ (рис. 6). Непокрытые частицы, полученные другими методами, являются токсичными для опухолевых и нормальных эпителиальных клеток при концентрации $400 \mu \mathrm{g} / \mathrm{ml}$, что совпадает с нашими данными, а при концентрации $50 \mu \mathrm{g} / \mathrm{ml}$ - только для нормальных эпителиальных клеток [19]. Скорость пролиферации и жизнеспособность являются показателями, отражающими состояние клетки и происходящие в ней изменения. То, что мы не обнаружили изменений при использовании широкого диапазона концентраций, позволяет говорить, что мечение непокрытыми IONP, полученными методом электрического взрыва в атмосфере воздуха, хорошо переносится клетками.

В исследовании использовали IONP, полученные методом сухого взрыва, что позволяет минимизировать присутствие различных примесей. Частицы, полученные таким способом, обладают формой, приближенной к сферической (рис. 2). Это, с одной стороны, облегчает процедуру измерения их диаметра и других расчетов, так 

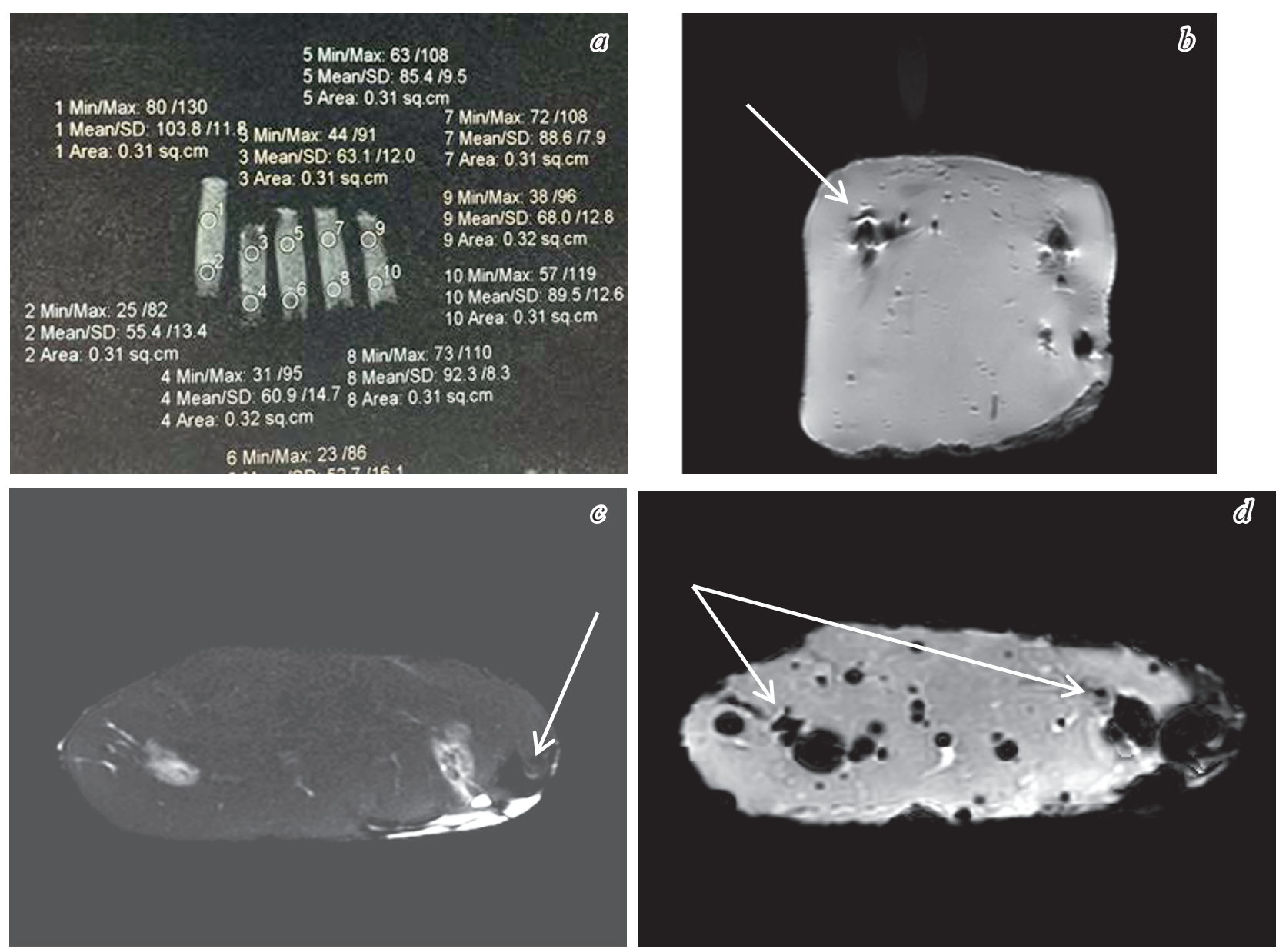

Рис. 6. Примеры изображений, полученных в ходе магнитно-резонансного сканирования меченых клеток, ресуспендированных в физиологическом растворе $(a)$ и инъецированных в ткани печени крупного рогатого скота $(b-d)$. $a-$ слева направо шприцы с физиологическим раствором без частиц, с клетками, после инкубации с IONP 100, 200, 300 $\mu \mathrm{g} / \mathrm{ml}$ и суспензия IONP $300 \mu \mathrm{g} / \mathrm{ml}$. Участки, для которых проводили измерения, пронумерованы цифрами. Значения плотности изображения и размера измеряемой области указаны на рисунке рядом с соответствующей цифрой. Стрелки на $b-d$ обозначают места инъекций с участками изменения интенсивности MР-сигнала. Изображение $(a)$ получено в режиме T2-TSE, $b-$ T1 dual WI TE $=2,3$, TR $=103, c-$ в T2 SPAIR $\mathrm{TE}=80, \mathrm{TR}=1250, d-\mathrm{T} 2^{*}$ gre $\mathrm{TE}=2,3, \mathrm{TR}=151$.

как отсутствует необходимость коррекции расчетов они основаны на допущении, что частицы имеют сферическую форму [20]. С другой стороны, IONP, по форме близкие к сфере, обладают рядом физических отличий от кубических или палочкообразных наночастиц, например, частицы разной формы могут различаться по коэрцитивности, блокирующей температуре, максимальным размером однодоменной структуры и т.д., различной величиной насыщающей магнетизации, что влияет на различные аспекты их практического применения $[5,21]$.

По данным измерений методами лазерной дифракции, DLS, а также электронной микроскопии, размер использованных в исследовании IONP варьировал в широких пределах — от 14 до $200 \mathrm{~nm}$, при этом диаметр 75\% частиц не превышал $136 \mathrm{~nm}$. Магнитные свойства наночастиц зависят от их размеров. Обязательным условием возникновения суперпарамагнитных свойств является однодоменность. Для каждого ферро- и ферримагнетика существует критический размер, ниже которого его частицы становятся однодоменными. При комнатной температуре критические размеры, определенные экспериментально для ферримагнетика $\mathrm{Fe}_{3} \mathrm{O}_{4}$, по различным данным составляют 50-53 nm [5,22]. По нашим данным (табл. 1), 25\% частиц в использованных нами суспензиях нанопорошка обладали таким размером. Однако свойства суперпарамагнитности проявляются только при размере частиц до $30 \mathrm{~nm}$ [23]. В используемых нами суспензиях количество таких частиц составляло около 10\%. Широкий диапазон размеров увеличивает возможности контрастирования при МРТ, так как позволяет использовать различные параметры получения изображений.

\section{Заключение}

На данном этапе показана возможность включения в клетки, непокрытых наночастиц, оксида железа, полу- 
ченных методом электрического взрыва проводника в атмосфере воздуха. Получаемые IONP обладают сферической или приближенной к ней формой, размер частиц варьирует от 14 до $200 \mathrm{~nm}$. Подобные свойства позволяют расширить набор параметров, позволяющих визуализировать меченые IONP-клетки.

\section{Благодарности}

Авторы выражают благодарность сотрудникам группы конфокальной микроскопии и анализа изображений Центра клеточных технологий Института цитологии РАН Г.И. Штейну и М.Л. Воробьеву за помощь в работе с конфокальным микроскопом Olympus FV3000 (Nikon, Japan).

\section{Финансирование работы}

Работа выполнена в рамках НИР (№ AААА-А18118052990081-0) Государственного задания Министерства здравоохранения Российской Федерации № 05600105-18-00.

\section{Конфликт интересов}

Авторы заявляют, что у них нет конфликта интересов

\section{Список литературы}

[1] Villa C., Erratico S., Razini P., Fiori F., Rustichelli F., Torrente Y., Belicchi M. // Int. J. Mol. Sci. 2010. Vol. 11. N 3. P. $1070-1081$. DOI: $10.3390 / \mathrm{ijms} 11031070$

[2] Korchinski D.J., Taha M., Yang R., Nathoo N., Dunn J.F. // Magn. Reson. Insights. 2015. N 8. S1. P. 15-29. DOI: 10.4137/MRI.S23557

[3] Киттель Ч. Введение в физику твердого тела. М.: Наука, 1978. C. 366.

[4] Жерновой А.И. // Научное приборостроение. 2018. Т. 28. № 2. C. 45-48.

[5] Kolhatkar A.G., Jamison A.C., Litvinov D., Willson R.C., Lee T.R. // Int. J. Mol. Sci. 2013. Vol. 14. N 8. P. 1597716009. DOI: $10.3390 / \mathrm{ijms} 140815977$

[6] Yudintceva N.M., Nashchekina Y.A., Blinova M.I., Smagina L.V., Shevtsov M.A., Voronkina I.V. // FEBS J. 2017. Vol. 284. N S1. P. 382. DOI: $10.1111 /$ febs. 14174

[7] Wahajuddin, Arora S. // Int. J. Nanomedicine. 2012. Vol. 7. P. 3445-3471. DOI: 10.2147/IJN.S30320

[8] Elkhenany H., Abd Elkodous M., Ghoneim N.I. Ahmed T.A., Ahmed S.M., Mohamed I.K., El-Badri N. // Int. J. Biol. Macromol. 2019. DOI: 10.1016/j.ijbiomac.2019.10.031

[9] Arias L.S., Pessan J.P., Vieira A.P.M., Toito de Lima T.M., Delbem A.C.B., Monteiro D.R. // Antibiotics (Basel). 2018. Vol. 7. N 2. P. 46. DOI: $10.3390 /$ antibiotics 7020046

[10] Jordan A., Wust P., Scholz R., Tesche B., Fähling H., Mitrovics T., Vogl T., Cervós-Navarro J., Felix R. // Int. J. Hyperthermia. 1996. Vol. 12. N 6. P. 705-722.

DOI: $10.3109 / 02656739609027678$

[11] Feng Q., Liu Y., Huang J., Chen K., Huang J., Xiao K. // Sci. Rep. Vol. 8. N 1. P. 2082. DOI: $10.1038 / \mathrm{s} 41598-018-19628-\mathrm{z}$
[12] Автореф. канд. дис. Лернер М.И. Электровзрывные нанопорошки неорганических материалов: технология производства, характеристики, области применения: 01.04.07. 2007. $325 \mathrm{c}$.

[13] Лернер М.И., Сваровская Н.В., Псахье С.Г., Бакина О.В. // Российские нанотехнологии. 2009. Т. 4. № 11-12. С. 56-68.

[14] DelsaMax PRO Light Scattering Analyzer. Instructions for Use. // Beckman Coulter, Inc. 2013. P. 188.

[15] Mindukshev I., Gambaryan S., Kehrer L., Schuetz C., Kobsar A., Rukoyatkina N., Nikolaev V.O., Krivchenko A., Watson S.P., Walter U., Geiger J. // Clin. Chem. Lab. Med. 2012. Vol. 50. N 7. P. 1253-1262.

[16] Айзенштадт А.А., Енукашвили Н.И., Золина Т.Л. Александрова Л.В., Смолянинов А.Б. // Вестник СевероЗападного гос. мед. ун-та им. И.И. Мечникова. 2015. Т. 7. № 2. C. 14-22.

[17] Багаева В.В., Айзенштадт А.А., Александрова Л.В. и др. // Изобретения. Полезные модели. Официальный бюллетень Федеральной службы по интеллектуальной собственности, патентам и товарным знакам. 2017. № 16. RU 2620981 C2. C. 1-2.

[18] Dominici M., Le Blanc K., Mueller I., Slaper-Cortenbach I., Marini F., Krause D., Deans R., Keating A., Prockop Dj., Horwitz E. // Cytotherapy. 2006. Vol. 8. N 4. P. 315-317. DOI: $10.1080 / 14653240600855905$

[19] Li L., Mak K.Y., Shi J., Koon H.K., Leung C.H., Wong C.M., Leung C.W., Mak C.S., Chan N.M., Zhong W., Lin K.W., Wu E.X., Pong P.W. // J. Nanosci. Nanotechnol. 2012. Vol. 12. N 12. P. 9010-9017. DOI: 10.1166/jnn.2012.6755

[20] Das R., Das B.K., Shukla R., Shyam A. // J. Phys.: Conf. Series. 2012. Vol. 390. N 1. P. 2051. DOI: $10.1088 / 1742-6596 / 390 / 1 / 012051$

[21] Li Q., Kartikowati C.W., Horie S., Ogi T., Iwaki T., Okuyama K. // Sci. Rep. 2017. Vol. 7. N 1. P. 9894. DOI: $10.1038 / \mathrm{s} 41598-017-09897-5$

[22] Абрамов Н.В., Горбик П.П. // Поверхность. 2012. Вып. 4. C. $246-265$.

[23] Jeong U., Teng X., Wang Y., Yang H., Xia Y. // Adv. Mater. 2007. Vol. 19. N 1. P. 33-66. DOI: 10.1002/adma.200600674 